\title{
Multiprofessional care in forensic psychiatry
}

\author{
Realities and constraints
}

\author{
N. V. Griffin, Consultant Forensic Psychiatrist, Reaside Clinic, Rednal, Birmingham \\ B45 9BE
}

The concept of multidisciplinary care has arisen from the recognition that there are many areas in medicine and psychiatry which require professional skills and expertise in addition to those possessed by doctors and nurses. The attitude of psychiatrists towards this development has varied from enthusiasm to alarm. Whereas the latter may be understandable in the face of recent publications which portray the profession as being under threat, Bennett (1988) has addressed these changes in a positive manner, and it is surely more responsible to regard the emergence of related professions as a source of assistance rather than hazard.

The practitioners of forensic psychiatry are obliged to consider in more depth than usual matters such as deviant behaviour, dangerousness, the multifaceted problem of personality disorder, ethical issues and the criminal justice system. The requirement for close interdisciplinary co-operation has therefore received much attention, for example from the influential Butler Committee (Home Office and DHSS, 1975). The recent discussion paper on 'The Role, Responsibilities and Work of the Consultant Forensic Psychiatrist' (Royal College of Psychiatrists, 1988) makes a statement about multidisciplinary care, which appears to emphasise the role of the Responsible Medical Officer at the expense of the multidisciplinary process:

"Whilst the concept of the multidisciplinary team is accepted as desirable practice, the ultimate authority for admission, treatment, discharges and aftercare remains with the Responsible Medical Officer".

It is appropriate to refer to a Regional Psychiatric Service, together with related agencies such as the Probation Service, as a multidisciplinary network. The following discussion, however, refers mainly to the multidisciplinary clinical team, whose members meet on a regular and frequent basis, and in which firm working relationships are established.

\section{Models of multidisciplinary care}

The term 'multidisciplinary care' is now frequently used but is rarely described, or discussed. It should refer to more than simply the membership of the team. The essential elements of the multidisciplinary process are the integration of the separate perspectives, knowledge and skills of the health care professionals involved, without blurring of interdisciplinary boundaries or loss of professional independence. Two contrasting types of multidisciplinary care, characterised by the degree to which individual team members may function autonomously, have been described (British Psychological Society, 1986).

The 'Overall Leadership Model' refers to: "A group of people with a designated leader who may or may not consult with others, and who may override the recommendations of others".

At its simplest, this is the situation where team members supply information to the consultant, witness the machinery of medical decision making, and have tasks delegated to them. Whereas the roles and responsibilities of team members are relatively clear, and the consultant benefits from opinions of other professionals, the collective decision making process is absent. The team can only operate at the highest levels of the leader's skills in any area of its functioning, and the under-valuation and under-utilisation of the expertise of non medical members may lower morale.

The alternative could be termed the 'Multiprofessional Model'. The term 'professional' implies special training, competence, self regulation and high standards imposed by a professional body. Most psychiatrists would willingly accord this status to nurses, occupational therapists, psychologists, social workers and others. Nevertheless the adoption of a 'Multiprofessional Model' has implications that might at first alarm, although they carry with them the crucial elements of the optimal team approach.

This type of team is described as a group of people from different professions with the following characteristics.

Each member has equal clinical authority, certainly within their own areas of competence.

Each member has direct personal legal responsibility for their actions and omissions.

Decisions about a patient's care and treatment are arrived at by consensus. 
No single member is able to override others, except in decisions which require the exclusive professional expertise of an individual.

There is mutual respect for the roles and skills of each team member.

When this approach is working effectively there is integration of the knowledge, perspectives and skills of each team member for the optimum operation of collective decision making. The team is able to function at the highest level of available expertise, morale will be higher and the whole process more enjoyable. Unfortunately there are real problems if the team does not function well. The whole mechanism may be unwieldy with interminable discussion of contentious issues without a clear decision. Roles and responsibilities may not be clear, or may be the subject of perpetual arguments and power struggles. In these circumstances the team may function collectively at a level of competence well below that of each individual member. Despite these difficulties it is evident that the potential of this model should not be abandoned lightly, but before it can be adapted to the needs of forensic psychiatry some of the problems prominent in this speciality need to be examined.

\section{Safety}

Forensic psychiatry has a high public profile by virtue of the potential behaviour of the patients. Its practitioners are therefore justifiably preoccupied with issues of safety, which in this context can be defined as the protection of the public from the patients, and the protection of the good name of the service in order to allow it to continue effectively. Before the considerable safety inherent in effective collective decision making can be employed, however, the team requires organisation, accountability and leadership.

\section{Clinical responsibility}

The term responsibility encompasses notions of personal and moral commitment, legal accountability, delegated authority, contractural obligations and probably others (British Psychological Society, 1986). These separate aspects are often unrecognised or ignored, and the debate over who has responsibility, with the related leadership issues, is therefore often heated, irrational and unproductive.

Doctors usually commit themselves to providing the best possible treatment. The medical tradition of care does not however, exclude other professionals from the same ideals. Most doctors are also concerned about their legal responsibilities and the risk of being sued. Here again the doctor is not alone, for all professionals have a duty of care, and all can be sued for negligence within their own sphere of expertise. Nevertheless in hospital the consultant, and in the community the general practitioner, do have a delegated responsibility for the overall management of a patient on behalf of the health authority, yet a consultant cannot be expected to make every decision concerning a patient's management, as many of these will fall within the expertise and responsibilities of other professionals.

This mingling of responsibilities is a complicated issue. Perhaps the best advice was that given by the DHSS subcommittee on 'The Role of Psychologists in the Health Service' (1977), which identified the simultaneous existence of "Full Clinical Responsibility" for the consultant or general practitioner, "Independent Professional Responsibility" for each team member, and "Shared Responsibility" for decisions taken by all team members together.

Finally, where patients are detained in hospital, or are subject to restriction orders, under the Mental Health Act 1983, the consultant has specified tasks as the Responsible Medical Officer. These are scattered throughout the text of the act, itself a source of some confusion, but come close to embracing total care.

\section{Leadership}

The need for accountability and structure suggests that a leader is necessary, and the responsibilities of the consultant together with those of the Responsible Medical Officer suggest that the tradition of medical leadership remains valid. Nevertheless it can be logically argued that leadership should naturally evolve rather than be imposed, that the required personal qualities cannot be learned or taught, and that different team members should assume this role in different circumstances. Directorship is preferable to chaos, but can be damaging to the multiprofessional process, and hence patient care, if the individual does not fully respect his/her professional colleagues.

\section{Comment}

Does the need for organisation, accountability, and medical leadership mean that the multiprofessional process has to be abandoned, with the loss of all its advantages? I believe not, provided the following conditions are met.

Each team member should have respect for the professional expertise, status, experience and individual skills of the others.

The specialist roles and responsibilities of each team member, including those of the Responsible Medical Officer, should be understood and defined to the satisfaction of the whole team.

Each team member should be prepared to participate in the collective decision making process, and to accept shared responsibility in defined areas. 
It is perhaps a paradox that the successful adoption of a multiprofessional approach requires the full support, and even leadership, of the consultant psychiatrist. Some would regard this as a professional own goal. Others, including myself, see it as an essential component of comprehensive care, in forensic psychiatry as much as any other field.

\section{References}

BENNETT, G. (1988) What should psychiatrists be doing in the 1990s? British Medical Journal, 296, 274-275.
British Psychological SOCIETY (1986) Responsibility Issues in Clinical Psychology and Multidisciplinary Teamwork. A Report by the Division of Clinical Psychology.

DHSS (1977) The Role of Psychologists in the Health Services. Report of the Sub-Committee. Chairman: Professor W. H. Trethowan. London: HMSO.

HoME OFFICE \& DHSS (1975) Report of the Committee on Mentally Abnormal Offenders (Butler Report). London: HMSO. Cmmnd 6244.

Royal College of Psychiatrists (1988) The role, responsibilities and work of the consultant forensic psychiatrist. A discussion document. Bulletin of the Royal College of Psychiatrists, 12, 246-249.

\title{
Confidential 'phone-in' for teenagers
}

\author{
Alexander Burnfield, Consultant in Child and Family Psychiatry, The Family \\ Consultancy, Charlton Road Health Centre, Andover, Hampshire SP10 3LD
}

Ocean Sound, an independent Hampshire radio station, broadcasts pop music on a channel known as 'Power FM'. The presenter/producer of Power FM occasionally asks a guest 'expert' to talk briefly about a particular subject and then listeners are invited to phone directly for a confidential talk during the following hour. At the end of the allotted hour the 'expert' comes on the air again with some concluding remarks and additional information.

\section{Preparation}

I agreed to take calls on Ocean Sound's 'Power FM' direct line between 9.30 and 10.30 p.m. one Thursday evening in January. The subject was 'emotional problems faced by young people during adolescence'. It was agreed that this would include family problems, difficulties at school or college, anxieties about physical development and problems in relationships.

I decided that the best way to prepare myself was to obtain background information from the
Winchester Health Authority's Education Centre Library and from 'Help for Health', a Wessex Regional Health Information Centre based in Southampton. The first of these provided me with an up-to-date list of local self-help groups and contacts relevant to the needs of adolescents. The second sent me a range of leaflets together with several lists of local groups, contacts and counselling telephone numbers.

My wife, Penny, and I organised this information before the broadcast. The leaflets ranged from 'acne' to 'AIDS' and from 'birth control' to 'how to stop smoking'. Contacts and telephone numbers of groups included 'anorexia nervosa', 'drug abuse', 'asthma' and 'depression', together with a variety of other subjects.

\section{The interview}

We eventually found 'Ocean Sound' on a deserted industrial estate, and decided that while I answered the telephone calls Penny would pass me appropriate 